\title{
GÊNERO E AGRICULTURA: A SITUAÇÃO DA MULHER NA AGRICULTURA DO RIO GRANDE DO SUL
}

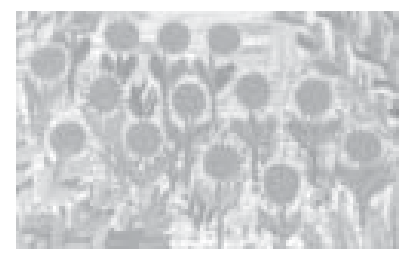

ANITA BRUMER

Universidade Federal do Rio Grande do Sul

Resumo: O texto examina as formas de inserção das mulheres na agricultura familiar, procurando explicar a seletividade de gênero do processo migratório. Primeiramente, aborda a distribuição da população, por sexo e por grupos de idade, em diversas regiões do Estado do Rio Grande do Sul, caracterizando o maior índice de emigração de mulheres jovens do que dos demais grupos etários e de sexo. Depois, trata da divisão do trabalho por sexo e idade, dos efeitos da modernização sobre o trabalho agrícola, da inserção dos jovens no trabalho da unidade produtiva familiar, das atividades fora da agricultura e dos procedimentos utilizados pelos produtores agrícolas para a transmissão da propriedade rural para os filhos. Finalmente, discute o possível efeito do acesso das mulheres rurais à Previdência Rural sobre suas perspectivas de permanecer ou não na atividade agrícola.

Palavras-chave: gênero e agricultura, mulher rural, migração rural.

\section{Introdução}

O objetivo deste trabalho é analisar as causas da mais acentuada migração ruralurbana de moças do que de rapazes rurais, com base na forma de inserção das mulheres na unidade de produção familiar agrícola e em transformações recentes ocorridas na agricultura e na sociedade do Rio Grande do Sul, situado no extremo sul do Brasil. ${ }^{1}$ Apresentam-se, inicialmente, um panorama sintético sobre a agricultura do Estado e os dados referentes à emigração seletiva, para depois serem examinadas algumas características da forma de inserção de mulheres e dos jovens na agricultura familiar, tais como: a) a divisão do trabalho por sexo e geração; b) os efeitos da modernização da agricultura sobre a divisão do trabalho por sexo; c) as características do trabalho dos jovens na unidade de produção familiar; d) o trabalho em tempo parcial ou fora da agricultura; e) as práticas de transmissão da propriedade familiar. Finalmente, consideramse as conquistas recentes das mulheres referentes aos benefícios da Previdência Social, discutindo-se seus possíveis efeitos sobre a situação de trabalho da mulher rural.

Copyright (c) 2004 by Revista Estudos Feministas

1 Uma versão anterior deste trabalho foi apresentada no XXII Congresso Internacional da Latin American Studies Association (LASA), Hyatt Regency Miami, de 16 a 18 de março de 2000. 
Para fazer a análise, são examinados dados quantitativos obtidos em uma ampla pesquisa realizada pela Emater/RS, órgão de extensão rural do Rio Grande do Sul, em 1991/1992, ${ }^{2}$ e em estudos específicos realizados em alguns municípios do Estado com predominância da agricultura familiar.

\section{A agricultura do Rio Grande do Sul}

Para uma breve descrição da economia do Rio Grande do Sul, o Estado pode ser dividido em três grandes regiốes, ${ }^{3}$ com base em sua homogeneidade histórica. A região Sul caracteriza-se pela concentração da posse da terra - estrutura fundiária herdada do período colonial - e, como conseqüência, pela concentração da renda, por centros urbanos esparsos e pela reduzida densidade da população rural. Ocupando um pouco mais da metade do território gaúcho, a Região Sul possui uma área relativamente plana a zona de campos -, onde predominam a pecuária e, a partir dos anos 1970, as lavouras modernizadas e mecanizadas de arroz, soja e trigo. A região Nordeste, constituída pelo eixo Porto Alegre-Caxias do Sul e por algumas áreas no seu entorno, é a região mais industrializada e urbanizada do Estado. Em sua agricultura predominam as pequenas propriedades. A região Norte, que compreende, grosso modo, a zona de vales e planaltos, com cobertura vegetal de matas, é fundamentalmente agrária. A estrutura econômica da região foi fortemente influenciada pela imigração de europeus não ibéricos e de seus descendentes, procedentes de áreas coloniais mais antigas, onde praticavam a agricultura com base na pequena e na média propriedade. Como indicam Alonso e Bandeira, "trata-

\footnotetext{
${ }^{2}$ A pesquisa da Emater consistiu em um levantamento de dados realizado entre março de 1991 e maio de 1992, com base em uma amostra de 3.584 estabelecimentos agropecuários do Rio Grande do Sul. Em um primeiro momento, foram selecionados alguns municípios-tipo representantes das nove microrregióes administrativas da Emater/RS. Posteriormente, foi feita a seleção de uma amostra probabilística e randômica metrificada dos estabelecimentos agropecuários dos municípios selecionados. As nove regiões, os respectivos municípios selecionados e o número de estabelecimentos incluídos na amostra são os seguintes: 1) Campanha (Alegrete, São Gabriel, Santana da Boa Vista) - 280 estabelecimentos; 2) Serra (Farroupilha, Lagoa Vermelha, Nova Petrópolis, Nova Prata, André da Rocha, Caseiros, Guabiju) - 311 estabelecimentos; 3) Vale do Taquari (Barros Cassal, Encantado, Estrela, Guaporé, Montenegro, Venâncio Aires, Teutônia, Dois Lajeados, Harmonia, Imigrante, Relvado) - 600 estabelecimentos; 4) Planalto (Carazinho, Frederico Westphalen, Sarandi, Tapera) 260 estabelecimentos; 5) Zona Sul (Arroio Grande, Pelotas, Piratini, Rio Grande, Capão do Leão, Morro Redondo) - 411 estabelecimentos; 6) Metropolitana (Barra do Ribeiro, Butiá, Gravataí, Mostardas, Rolante, Santo Antonio da Patrulha, Tavares, Glorinha, Três Cachoeiras) - 485 estabelecimentos; 7) Depressão Central (Cruz Alta, Restinga Seca, Santiago, São Pedro do Sul, Sobradinho) - 467 estabelecimentos; 8) Noroeste (Campina das Missões, Crissiumal, Panambi, Santo Augusto, São Luis Gonzada, Tuparendi) - 470 estabelecimentos; 9) Alto Uruguai (Aratiba, Campinas do Sul, Getúlio Vargas, Machadinho, Erebango, Estação, Ipiranga do Sul) - 300 estabelecimentos. Por seu tamanho, a amostra parece ser boa em termos de representatividade. É preciso levar em conta, porém, que os municípios-tipo são representativos das regiões administrativas da Emater/RS e que as informações referentes a alguns municípios selecionados só podem ser generalizadas após um exame cuidadoso. Destaca-se que as nove regiões administrativas da Emater/RS não se baseiam, necessariamente, em indicadores sócio-econômicos e não correspondem completamente às sete regiões utilizadas pelo IBGE. Além disso, por ter sido utilizada uma amostra aleatória não estratificada, há uma tendência de sub-representatividade dos estabelecimentos agropecuários maiores. Uma análise desses dados foi feita anteriormente em BRUMER, 1999.

${ }^{3}$ Ver o trabalho de José Antonio Fialho ALONSO, Maria Domingues BENETTI e Pedro Silveira BANDEIRA, 1994. As três regiões em que o Estado foi subdividido nesse trabalho correspondem, grosso modo, às seguintes regióes utilizadas pela Emater/RS: a região Sul inclui as sub-regiões da Campanha e Zona Sul, assim como alguns municípios incluídos na Depressão Central e na sub-região Metropolitana; a região Norte compreende a maior parte das sub-regiões Planalto, Noroeste e Alto Uruguai, assim como parte da sub-região Depressão Central; a região Noroeste está representada pelas sub-regióes Serra, Vale do Taquari e grande parte da região Metropolitana.
} 
se de uma região muito heterogênea, onde uma produção inicialmente muito diversificada tendeu a ceder, paulatinamente, em muitas áreas, espaço para as lavouras mecanizadas do trigo e da soja". ${ }^{4}$ Alguns municípios dessa região conseguiram, com o passar do tempo, sediar algum crescimento industrial diretamente vinculado à produção primária, tais como o processamento de produtos agrícolas locais e a produção de insumos e implementos para a lavoura. ${ }^{5}$

Considerando todo o Estado, a estrutura agrária apresenta um alto grau de concentração das terras e o predomínio de pequenas e médias propriedades: em 1995, os estabelecimentos com menos de 10 hectares representavam 35,1\% do total e ocupavam $3,4 \%$ da área total; os estabelecimentos com área de 10 a menos de 100 hectares representavam $57,0 \%$ do total e ocupavam $29,5 \%$ da área; os estabelecimentos de 100 a menos de 1.000 hectares representavam $7,2 \%$ do total e ocupavam $40,5 \%$ da área; os estabelecimentos com área de 1.000 a menos de 10.000 hectares representavam $0,7 \%$ do total e ocupavam $25,7 \%$ da área, enquanto que os estabelecimentos com 10.000 hectares e mais representavam menos de $0,1 \%$ do total e ocupavam $0,9 \%$ da área. ${ }^{6}$

Estima-se que a produção familiar caracterize de um modo geral a maioria dos estabelecimentos agropecuários do Estado com área inferior a 100 hectares, abrangendo, assim, cerca de $90 \%$ do total.

\section{A seletividade da migração rural-urbana por idade e sexo}

A população do Rio Grande do Sul, de acordo com a Contagem da População do IBGE, em 1996, é atualmente de cerca de 10 milhões de indivíduos (9.637.682, em 1996), dos quais, por ocasião do levantamento dos dados, 78,7\% viviam na zona urbana e $21,3 \%$ na zona rural. Comparando esses números com os resultados de censos anteriores, constatase a progressiva urbanização da população do Estado, isto é, a progressiva perda da importância da população rural no conjunto da população: a população rural representava $65,9 \%$ da população total do Rio Grande do Sul em 1950, 55,1\% em 1960, 46,7\% em $1970,32,45 \%$ em 1980, 23,4\% em 1991 e $21,3 \%$ em 1996.

A população do Estado, em 1996, distribuía-se em 50,8\% do sexo feminino e 49,1\% do sexo masculino, caracterizando-se pela presença de mais mulheres do que homens no meio urbano e de um número maior de homens do que de mulheres no meio rural: no meio rural gaúcho havia, em 1996, 89.782 homens a mais do que mulheres, enquanto que na zona urbana a situação era invertida, pois havia 248.708 mulheres a mais do que homens. $^{7}$

Os dados acima indicam, por um lado, a continuada migração rural-urbana, embora com um ímpeto menor na década de 90 relativamente às décadas anteriores; por outro lado, considerando-se que nasce aproximadamente a mesma proporção de bebês do sexo masculino e do sexo feminino, ocorre uma seletividade no processo migratório, caracterizada pela maior proporção de migrantes do sexo feminino do que do sexo masculino.

É preciso levar em conta, ainda, que, em diferentes regiões do Estado, varia a proporção de homens e de mulheres (cf. quadro 1), assim como varia a distribuição da população por idade.

\footnotetext{
${ }^{4}$ ALONSO e BANDEIRA, 1994, p. 224.

${ }^{5}$ ALONSO E BANDEIRA, 1994, p. 224.

${ }^{6}$ IBGE, 1998.

7 IBGE, 1996.
} 
Em uma pesquisa realizada pela Emater, em 1991/1992, verificou-se a existência de uma maior proporção de idosos (pessoas com mais de 65 anos) em algumas regiões do que em outras (cf. quadro 2). As regiões com um número proporcionalmente maior de idosos são Campanha, Metropolitana, Zona Sul e Serra (com respectivamente 9,2\%, 9,4\%, $10,5 \%$ e 10,6\%, enquanto que nas demais regiões a proporção de idosos varia de 5,4\%, na região Noroeste, a 7,8\%, no Vale do Taquari). Aparentemente, as diferenças na distribuição da população por idade, entre as regiões, além de terem como causa variações nas taxas de fecundidade (ou fertilidade) e nas taxas de mortalidade, podem ser explicadas por diferentes índices migratórios - que, como veremos mais adiante, podem, por sua vez, ser em parte explicados por diferentes condições de vida e de trabalho no meio rural.

O caráter seletivo do processo migratório é evidenciado nos dados da pesquisa da Emater, pois, quando se examina a distribuição da população rural por grupos de idade e por sexo, a maior diferença na proporção em que homens e mulheres estão representados no conjunto da população rural ocorre na faixa etária de 20 a 25 anos (na qual 9, 15\% são do sexo feminino e $11,4 \%$, do sexo masculino). De fato, examinando-se os números absolutos (ver quadro 3), em todos os grupos de idade a população masculina é maior que a feminina, e a diferença numérica entre os sexos atinge seu ápice na faixa etária de 20 a 25 anos. Isto é, o processo migratório é seletivo por sexo e por idade, uma vez que a maior proporção de emigrantes rurais é do sexo feminino e essa defasagem ocorre mais acentuadamente entre os jovens de 20 a 25 anos.

\section{QUADRO 1 - DISTRIBUIÇÃO DA POPULAÇÃO RURAL DO RIO GRANDE DO SUL, POR REGIÃO E SEXO}

\begin{tabular}{|l|l|l|l|}
\hline Regiões & Homens & Mulheres & Total \\
\hline Campanha & $473(55,7 \%)$ & $376(44,3 \%)$ & $849(100 \%)$ \\
\hline Serra & $646(53,8 \%)$ & $554(46,2 \%)$ & $1.200(100 \%)$ \\
\hline Vale Taquari & $1.273(52,9 \%)$ & $1.135(47,1 \%)$ & $2.408(100 \%)$ \\
\hline Planalto & $579(52,9 \%)$ & $516(47,1 \%)$ & $1.095(100 \%)$ \\
\hline Zona Sul & $799(52,3 \%)$ & $730(47,7 \%)$ & $1.529(100 \%)$ \\
\hline Metropolitana & $977(53,3 \%)$ & $856(46,7 \%)$ & $1.833(100 \%)$ \\
\hline Depressão Central & $1.022(51,9 \%)$ & $947(48,1 \%)$ & $1.969(100 \%)$ \\
\hline Noroeste & $999(53,6 \%)$ & $866(46,4 \%)$ & $1.865(100 \%)$ \\
\hline Alto Uruguai & $658(51,9 \%)$ & $611(48,1 \%)$ & $1.269(100 \%)$ \\
\hline Total & $7.426(53 \%)$ & $6.591(47 \%)$ & $14.017(100 \%)$ \\
\hline
\end{tabular}

FONTE: PESQUISA RURAL - EMATER, 1992 
QUADRO 2 - DISTRIBUIÇÃO DA POPULAÇÃO RURAL DO RIO GRANDE DO SUL POR REGIÕES E GRUPOS DE IDADE

\begin{tabular}{|l|l|l|l|l|l|l|l|l|l|}
\hline $\begin{array}{l}\text { Grupos de Campanno } \\
\text { idade } \\
\text { (anos) } \%\end{array}$ & $\%$ & $\begin{array}{l}\text { Serra } \\
\%\end{array}$ & $\begin{array}{l}\text { Vale do } \\
\text { Taquari } \\
\%\end{array}$ & $\begin{array}{l}\text { Planalto } \\
\%\end{array}$ & $\begin{array}{l}\text { Zona } \\
\text { Sul } \\
\%\end{array}$ & $\begin{array}{l}\text { Metro- } \\
\text { politana } \\
\%\end{array}$ & $\begin{array}{l}\text { Depressão } \\
\text { Central } \\
\%\end{array}$ & $\begin{array}{l}\text { Noroeste } \\
\%\end{array}$ & $\begin{array}{l}\text { Alto } \\
\text { Uruguai } \\
\%\end{array}$ \\
\hline Até 5 & 5,4 & 5,1 & 5,9 & 7,8 & 5,3 & 5,0 & 5,1 & 6,5 & 6,5 \\
\hline $6-15$ & 13,2 & 15,7 & 16,4 & 17,7 & 16,2 & 15,6 & 16,5 & 18,9 & 17,8 \\
\hline $16-20$ & 8,5 & 8,3 & 10,1 & 9,2 & 8,9 & 9,6 & 10,0 & 10,6 & 10,1 \\
\hline $21-25$ & 6,6 & 8,4 & 9,6 & 8,4 & 7,1 & 7,7 & 7,9 & 8,4 & 9,7 \\
\hline $26-40$ & 22,0 & 18,8 & 19,3 & 23,2 & 20,6 & 19,4 & 22,9 & 21,3 & 20,9 \\
\hline $41-65$ & 34,9 & 33,3 & 30,9 & 26,5 & 31,3 & 33,2 & 30,7 & 28,8 & 28,5 \\
\hline + de 6 & 59,2 & 10,4 & 7,9 & 7,1 & 10,6 & 9,5 & 6,9 & 5,4 & 6,5 \\
\hline Total & 100 & 100 & 100 & 100 & 100 & 100 & 100 & 100 & 100 \\
\hline No Total & 939 & 1.303 & 2.648 & 1.265 & 1.684 & 1.972 & 2.026 & 2.028 & 1.410 \\
\hline
\end{tabular}

FONTE: PESQUISA RURAL - EMATER, 1992

QUADRO 3 - DISTRIBUIÇÃO POR IDADE E SEXO DA POPULAÇÃO RURAL DO RIO GRANDE DO SUL - 1992

\begin{tabular}{|l|l|l|l|l|}
\hline $\begin{array}{l}\text { Grupos de } \\
\text { idade (anos) }\end{array}$ & Homens & Mulheres & Total & $\begin{array}{l}\text { Diferença } \\
\text { (homens } \\
- \text { mulheres) }\end{array}$ \\
\hline $7-14$ & $1.036(13,8 \%)$ & $1.016(15,1 \%)$ & $2.052(14,4 \%)$ & $20(1,0 \%)$ \\
\hline $15-19$ & $792(10,6 \%)$ & $667(9,9 \%)$ & $1.459(10,3 \%)$ & $125(8,6 \%)$ \\
\hline $20-25$ & $919(12,3 \%)$ & $658(9,8 \%)$ & $1.577(11,1 \%)$ & $261(16,5 \%)$ \\
\hline $26-40$ & $1.666(22,2 \%)$ & $1.513(22,5 \%)$ & $3.179(22,4 \%)$ & $153(4,8 \%)$ \\
\hline $41-65$ & $2.435(32,5 \%)$ & $2.274(33,9 \%)$ & $4.709(33,2 \%)$ & $161(3,4 \%)$ \\
\hline+ de 65 & $640(8,5 \%)$ & $586(8,7 \%)$ & $1.226(8,6 \%)$ & $54(4,4 \%)$ \\
\hline Total & $7.488(100 \%)$ & $6.714(100 \%)$ & $14.202(100 \%)$ & $774(5,4 \%)$ \\
\hline
\end{tabular}

FONTE: PESQUISA RURAL - EMATER, 1992 
Como indica John Durston, a emigração rural-urbana pode ser boa ou danosa para o sistema sócio-econômico rural, de acordo com a situação específica de cada comunidade e de cada família:

Em contextos de extrema pobreza, de minifúndios crescentemente mais fragmentados e solos cada vez menos férteis, a emigração de uma parte de cada geração de jovens rurais pode contribuir para frear a crescente pauperização e para restaurar um equilíbrio no meio ambiente urbano. [...] Em outros contextos locais, entretanto, uma emigração excessiva ou muito seletiva dos jovens mais empreendedores e mais educados, ou viesada por sexo, pode dificultar a reprodução de lares e de instituições produtivas e comunitárias, prejudicando o tecido social rural loca.

Nesse sentido, as informações disponíveis sobre a população rural do Rio Grande do Sul apontam para duas questões problemáticas: a) o aumento do número de homens celibatários no meio rural, com conseqüências sobre o desenvolvimento de atividades produtivas agrícolas, tendo em vista o importante papel desempenhado pelas mulheres como mão-de-obra familiar não remunerada; b) a defasagem entre o número de moças e o de rapazes, o que pode 'forçar' um número maior de rapazes a emigrar, tendo em vista que raramente os jovens rurais encontram parceiras originárias do meio urbano que se disponham a viver no meio rural. É interessante destacar que a emigração rural, no Rio Grande do Sul, é acompanhada, por um lado, por uma drástica redução da taxa de fecundidade rural, que passou de 5,62 filhos por mulher de 15 a 44 anos, em 1970, para 3,78 em 1980, 2,78 em 1990 e 2,62 em 1995..$^{9}$ Por outro lado, o Estado é palco de um importante movimento de luta pela terra que, com sua atuação, desde o final dos anos 70 , tem obtido algumas vitórias, em um plano de reforma agrária que assentou 5.790 famílias, em mais de 100 mil hectares, entre 1978 e $1997 .{ }^{10}$

\section{Fatores explicativos da seletividade do processo migratório}

A seletividade da migração por idade e sexo pode ser explicada, em grande parte, pela falta de oportunidades existentes no meio rural para a inserção dos jovens, de forma independente da tutela dos pais; pela forma como ocorre a divisão do trabalho no interior dos estabelecimentos agropecuários e pela relativa invisibilidade do trabalho executado por crianças, jovens e mulheres; pelas tradições culturais que priorizam os homens às mulheres na execução dos trabalhos agropecuários mais especializados, tecnificados e mecanizados, na chefia do estabelecimento e na comercialização dos produtos; pelas oportunidades de trabalho parcial ou de empregos fora da agricultura para a população residente no meio rural; e pela exclusão das mulheres na herança da terra.

\subsection{Divisão do trabalho por sexo e geração}

Diversos estudos que examinaram a divisão do trabalho por sexo na agricultura permitem concluir que as mulheres (e, de um modo geral, também as crianças e os jovens) ocupam uma posição subordinada e seu trabalho geralmente aparece como 'ajuda', mesmo quando elas trabalham tanto quanto os homens ou executam as mesmas atividades que eles.

\footnotetext{
${ }^{8}$ DURSTON, s/d.

${ }^{9}$ Os dados foram calculados pelos técnicos do Núcleo de Sistematização de Indicadores da Fundação de Economia e Estatística (FEE), do Governo do Estado do Rio Grande do Sul, com base nas informações do IBGE (censos de 1970 e 1980), estimativas para 1990 referidas no censo de 1991 (IBGE, 1995a) e estimativas para 1995 com base na PNAD (Pesquisa Nacional de Amostra de Domicílios) de 1995 (IBGE, 1995b).

${ }^{10}$ Zander NAVARRO, Maria Stela MORAES e Raul MENEZES, 1999, p. 44.
} 
Em uma pesquisa realizada em Cruzeiro do Sul (RS), Anita Brumer e Nádia Maria Schuch Freire verificaram que,

na divisão de trabalho que se estabelece entre os sexos, ao homem cabe geralmente a exclusividade de desenvolver serviços que requerem maior força física, tais como lavrar, cortar lenha, fazer curvas de nível, derrubar árvores e fazer cerca. Também cabe ao homem o uso de maquinário agrícola mais sofisticado, tal como o trator. À mulher, de um modo geral, compete executar tanto as atividades mais rotineiras, ligadas à casa ou ao serviço agrícola, como as de caráter mais leve. Entre as tarefas em geral executadas pelas mulheres estão praticamente todas as atividades domésticas, o trato dos animais, principalmente os menores (galinhas, porcos e animais domésticos), a ordenha das vacas e o cuidado do quintal, que inclui a horta, o pomar e o jardim."

É preciso destacar que o caráter de 'pesado' ou 'leve' da atividade é relativa e culturalmente determinada, uma vez que, na esfera de suas atividades (doméstica), a mulher executa tanto trabalhos 'leves' como trabalhos 'pesados' (como trabalhar na colheita dos produtos agrícolas, carregar os filhos e buscar água em lugares distantes do domicílio). Essa constatação levou Maria Ignez Paulilo a concluir que "o trabalho é 'leve' (e a remuneração é baixa), não devido a suas características, mas devido à posição ocupada na hierarquia da família por aqueles que executam o trabalho". ${ }^{2}$

Em síntese, a posição subordinada das mulheres na esfera produtiva dos estabelecimentos agropecuários é assim evidenciada:

- as tarefas executadas no âmbito da esfera produtiva (produção destinada à comercialização) só são contabilizadas como parte de um esforço coletivo, na maioria das vezes aparecendo apenas como 'ajuda';

- seu trabalho na esfera produtiva permanece praticamente invisível, tendo em vista que é praticado no interior do estabelecimento, sendo os homens praticamente os únicos responsáveis pelos contatos com o exterior (contato com extensionistas, bancos, sindicato, cooperativa, firmas vendedoras de insumos e compradores);

- elas não detém o conhecimento tecnológico necessário para administrar o estabelecimento agropecuário;

- elas não administram os recursos originados com a venda da produção.

As atividades executadas preferencialmente por mulheres, crianças e jovens no meio rural caracterizam-se, de um modo geral, por serem relacionadas:

- principalmente à limpeza da terra e colheita, seleção e embalagem dos produtos;

- ao processamento dos produtos agrícolas;

- ao cuidado de animais, tais como alimentação, limpeza e ordenha;

- aos trabalhos da horta, principalmente se seus produtos forem destinados ao consumo da própria família.

As mulheres, ainda, responsabilizam-se praticamente sozinhas pelo trabalho

11 BRUMER E FREIRE, 1983/1984, p. 318.

12 PAULILO, 1987, p. 70. 
doméstico, no qual com freqüência são auxiliadas ou substituídas pelas filhas, quando têm outra atividade. Nessa esfera, as mulheres têm autonomia e poder, tomando decisões relativas ao preparo dos alimentos, cuidado da casa e da roupa, orientação e educação dos filhos, assim como ao uso de recursos destinados ao consumo doméstico. Elas também tomam decisões referentes a vendas eventuais de bens por elas produzidos, tais como ovos, queijo, nata, e outros, sendo também as responsáveis pelo uso dos recursos assim obtidos. No entanto, não se deve superestimar a importância de sua autonomia e poder nesse domínio, tendo em vista, por um lado, que as vendas feitas por elas geralmente são eventuais e de pequeno valor e, por outro, que as atividades domésticas são consideradas como secundárias, pelos próprios membros da família, em relação às atividades produtivas. Não é de surpreender, por isso, que muitas mulheres, apesar da dureza do trabalho agrícola e de seu papel subalterno no mesmo, prefiram exercer essa atividade ao trabalho doméstico, usando justificativas tais como: "o trabalho doméstico é todo dia a mesma coisa, a gente limpa e logo em seguida tem que limpar de novo"; "o trabalho na roça a gente vê". ${ }^{13}$

Dois aspectos podem explicar a divisão de trabalho que se estabelece entre homens e mulheres rurais. O primeiro é que a unidade familiar de produção caracteriza-se por reunir os esforços de todos os membros da família, com vistas ao benefício de todos, havendo uma necessária aproximação entre unidade de produção e unidade de consumo. $O$ segundo é que vivemos em uma sociedade paternalista, e de certo modo machista, em que se atribui ao homem o papel de responsável pelo provimento da família. Ocorre que as atividades geralmente desenvolvidas pelas mulheres na esfera produtiva dos estabelecimentos agropecuários requerem algumas qualidades que supostamente as mulheres (adultas e jovens) possuem (por natureza ou por aquisição, através do processo de socialização) ou que sua situação de trabalhadoras eventuais propicia (devido à manutenção de suas obrigações na esfera da reprodução). Entre essas qualidades, ${ }^{14}$ merecem destaque:

- a capacidade de executar tarefas repetitivas, tediosas e intensivas;

a capacidade de realizar várias tarefas ao mesmo tempo (uma característica de grande parte das atividades executadas no âmbito doméstico);

- a possibilidade de associar ao trabalho suas responsabilidades na esfera da reprodução, trazendo os filhos junto com elas para a roça ou afastando-se de suas residências por pouco tempo;

- devido a seus encargos na esfera doméstica, sua disponibilidade para envolver-se preferencialmente em trabalhos temporários, seja concentrados em determinados períodos durante o ano, seja ocupando apenas alguns dias da semana ou algumas horas durante 0 dia;

\footnotetext{
${ }^{13}$ FREIRE, 1983, p. 111.

${ }^{14}$ Esses atributos ou qualidades das mulheres não são exclusivos das mulheres rurais. Em um trabalho anterior, a autora deste texto, examinando a inserção das mulheres brasileiras no mercado de trabalho urbano, destacou alguns deles (BRUMER, 1988). Um dos aspectos examinados no referido texto diz respeito às principais ocupações profissionais das mulheres brasileiras reveladas pelo censo de 1980: 73\% das mulheres envolvidas em ocupações não-agrícolas concentravam-se em 10 atividades que tinham em comum características consideradas como 'femininas': servir, alimentar, limpar, cuidar de doentes e educar. Essas ocupações caracterizavam-se ainda por seu caráter subalterno e por terem menor prestígio e remuneração do que as atividades exercidas pelos homens (BRUMER, 1988, p. 23)
} 
- sua maior habilidade para execução de algumas tarefas que requerem dedos pequenos e ágeis, assim como a permanência em posição desconfortável (como trabalhar agachada) por bastante tempo;

- a aceitação de uma remuneração relativamente inferior à paga a homens ou a trabalhadores envolvidos em outras atividades;

- a maior docilidade (o que implica maior aceitação das exigências do trabalho e menor número de reivindicações).

\subsection{Modernização da agricultura e divisão do trabalho por sexo}

Graças à modernização da agricultura e à adoção de novas tecnologias, o trabalho produtivo tornou-se mais complexo, obrigando o produtor a investir em novos conhecimentos, a utilizar técnicas novas e a usar máquinas agrícolas, algumas delas bastante sofisticadas. Ao mesmo tempo, parte do trabalho que antigamente era feito à mão hoje pode ser feito com auxílio de máquinas, o que, em algumas situações, levou à diminuição do número de pessoas empregadas na agricultura. Como o responsável pela parte produtiva geralmente é o homem, é ele que investe no aprendizado das novas tecnologias, mantém os contatos com técnicos rurais ou agrônomos, faz a maioria das vendas e contatos com os bancos (empréstimos e pagamentos) e participa de associações tais como cooperativa e sindicato. São também os homens que administram os recursos oriundos da atividade agropecuária, pois, mesmo que as mulheres participem juntamente com os maridos na tomada de algumas decisões, são eles que conduzem o processo decisório quando se trata de investimentos referentes à produção ou à reposição dos meios de produção necessários para a safra seguinte, sendo significativa a participação da mulher, ou eventualmente de todos os membros da família, apenas nas despesas destinadas ao consumo doméstico ou nas despesas referentes ao atendimento de necessidades individuais de consumo. Se existem recursos excedentes - as 'sobras' - após o pagamento dos gastos de produção e atendidas as necessidades básicas de consumo, os homens é que os administram. Como regra geral, nem as mulheres nem os jovens têm uma renda própria, a não ser que os recursos sejam obtidos pela venda de seu trabalho a terceiros (trabalho assalariado) ou pela venda direta de produtos beneficiados por eles no estabelecimento familiar. Nesse sentido, deve ser destacado que homens e mulheres usam os eventuais recursos 'excedentes' de maneiras distintas, pois enquanto que eles privilegiam o consumo individual (bebida, lazer), elas favorecem as despesas com a casa e com o bem-estar dos membros da família. ${ }^{15}$

É possível constatar diferenças no emprego da mão-de-obra familiar em estabelecimentos de tamanhos (ou de importância econômica) distintos. Por exemplo, em uma pesquisa realizada em 1988 em ljuí, município situado na região Noroeste do Rio Grande do Sul, ${ }^{16}$ verificou-se a existência de correlação entre tamanho da propriedade e emprego de mão-de-obra familiar, além de diferenças na intensidade do emprego da mão-de-obra feminina e masculina de acordo com a área do estabelecimento (ver quadro 4). Assim, considerando-se o total de dias anuais de oito horas de trabalho dos membros

${ }^{15}$ Cornelia Butler FLORA e Blas SANTOS, 1986.

${ }^{16}$ A coleta de dados foi feita como parte de uma pesquisa comparativa sobre a produção familiar na agricultura em regiões distintas de cinco países: Brasil, França, Canadá, Polônia e Tunísia. Ver: Hughes LAMARCHE, 1993. Análises parciais sobre os dados coletados em ljuí estão em BRUMER e Elisa Olívia GIACOBBO, 1993, e BRUMER, 1994. 
da família (Unidade de Trabalho Homem, UTH), somando-se o tempo dedicado às tarefas produtivas por todos, separadamente, por sexo, nos estabelecimentos com área inferior a 10 hectares as mulheres trabalhavam mais que os homens (respectivamente 1,46 e 1,28 UTH); nos estabelecimentos com área entre 11 e 20 hectares o emprego de homens e mulheres era equivalente (1,25 UTH); nos estabelecimentos com área entre 21 e 40 hectares o trabalho masculino superava o feminino (respectivamente 1,58 e 0,89), mantendo-se esta relação nos grupos de áreas maiores. A diferença na intensidade de emprego de homens e de mulheres membros da família aprofundava-se à medida que aumentava a área do estabelecimento, pois os estabelecimentos com área superior a 40 hectares ocupavam, em média, 3,5 UTH, enquanto que os estabelecimentos com área inferior a 40 hectares ocupavam em média 2,5 UTH. ${ }^{17}$

\section{QUADRO 4 - RELAÇÃO ENTRE TAMANHO DO ESTABELECIMENTO AGROPECUÁRIO E EMPREGO DE MÃO-DE-OBRA FAMILIAR MASCULINA E FEMININA}

\begin{tabular}{|l|l|l|l|}
\hline $\begin{array}{l}\text { Área útil } \\
\text { (hectares) }\end{array}$ & $\begin{array}{l}\text { Número de } \\
\text { estabelecimento\$ }\end{array}$ & $\begin{array}{l}\text { UTH } \\
\text { Masculino }\end{array}$ & $\begin{array}{l}\text { UTH } \\
\text { Feminino }\end{array}$ \\
\hline Até 10 & 7 & 1,28 & 1,46 \\
\hline $11-20$ & 10 & 1,25 & 1,25 \\
\hline $21-40$ & 15 & 1,58 & 0,89 \\
\hline $41-100$ & 12 & 2,41 & 1,18 \\
\hline+ de 100 & 3 & 2,87 & 0,65 \\
\hline Média & - & 1,76 & 1,11 \\
\hline
\end{tabular}

FONTE: PESQUISA DE CAMPO, IJUÍ, $1988^{18}$

Como esses dados revelam, com muita freqüência, nos estabelecimentos maiores e mais tecnificados (exemplificados na amostra de ljuí pelos estabelecimentos com mais de 100 hectares), as esposas e filhas dos proprietários geralmente não participam ou participam de uma maneira menos intensiva das atividades produtivas, responsabilizandose quase que exclusivamente pelo trabalho doméstico, pelo cuidado da horta e, eventualmente, pelas atividades anexas (transformação artesanal de produtos agrícolas, por exemplo).

Em algumas situações, no entanto, a modernização das atividades implica a intensificação da agricultura, aumentando a carga de trabalho de todos os membros da família, mas mais intensamente das mulheres, considerando seu trabalho na esfera doméstica e no cuidado da horta. Como verificou Nádia Maria Schuch Freire, em pesquisa realizada em Cruzeiro do Sul (RS), "o uso da mecanização nestas pequenas propriedades deve ser visto como alternativa que o produtor utiliza para produzir em toda a terra que possui, obrigando os membros da família a prolongarem suas jornadas de trabalho". ${ }^{19}$ No caso estudado, a jornada média de trabalho das mulheres era de 16 horas diárias.

\footnotetext{
17 BRUMER E GIACOBBO, 1993.

${ }^{18}$ BRUMER Q GIACOBBO, 1993.

${ }^{19}$ FREIRE, 1983, p. 116.
} 


\subsection{Inserção dos jovens}

Os jovens são considerados parte da ajuda familiar, esperando-se que, com a vida adulta, constituam lares independentes. Como parte da ajuda familiar, trabalham como os outros e têm suas necessidades básicas atendidas no mesmo nível que os demais membros da família, mas devem pedir dinheiro aos pais quando pretendem ter alguma atividade de lazer fora do lar ou quando necessitam comprar algum objeto de uso pessoal.

Enquanto que os rapazes exercem suas atividades com os pais, participando juntamente com eles ou substituindo-os em algumas de suas responsabilidades, tal como a comercialização, especialmente se feita na estrada ou nos postos de comercialização, as moças exercem suas atividades junto com as mães, acompanhando-as no trabalho produtivo e nos afazeres do lar ou substituindo-as nas tarefas domésticas.

Recentemente, alguns produtores, em algumas regiões do Rio Grande do Sul, adotaram a estratégia de atribuir aos jovens um pedaço de terra, para que eles produzam na mesma de forma independente e usufruam seus benefícios, mantendo-os ao mesmo tempo como mão-de-obra auxiliar no restante da terra sob sua administração. Outros criaram uma espécie de 'parceria familiar', através da qual o filho ou os filhos (geralmente casados) que trabalham na propriedade familiar recebem uma parcela da produção.

\subsection{Agricultura em tempo parcial e empregos fora da agricultura}

Ocorre também, com alguma freqüência, e com intensidade diferente segundo as regiões do Estado, o trabalho de membros da família em atividades fora do estabelecimento agropecuário. Como se pode verificar nos quadros 5 e 6, o trabalho fora do estabelecimento envolve homens e mulheres, mas principalmente homens e mulheres jovens, com maior intensidade na faixa dos 20 a 25 anos de idade, quando atinge respectivamente $21,2 \%$ dos homens e $28,2 \%$ das mulheres do meio rural que trabalham, mas sendo importante na grande faixa que vai dos 15 aos 40 anos de idade; e atingindo mais as mulheres do que os homens.

O envolvimento de homens e mulheres em atividades em tempo integral ou parcial

QUADRO 5 - DISTRIBUIÇÃO DA POPULAÇÃO RURAL MASCULINA DO RIO GRANDE DO SUL, PELO TIPO DE TRABALHO (EM TEMPO INTEGRAL OU PARCIAL NO ESTABELECIMENTO AGROPECUÁRIO OU FORA DO ESTABELECIMENTO), DE ACORDO A IDADE

\begin{tabular}{|l|l|l|l|l|}
\hline Grupos de idade & $\begin{array}{c}\text { Tempo integralno } \\
\text { estabelecimento }\end{array}$ & $\begin{array}{c}\text { Tempo parcial no } \\
\text { estabelecimento }\end{array}$ & $\begin{array}{c}\text { Fora do } \\
\text { estabelecimento }\end{array}$ & Total \\
\hline 7-14 anos & $414(48,6 \%)$ & $376(42,2 \%)$ & $82(9,2 \%)$ & $892(100 \%)$ \\
\hline $15-19$ anos & $525(67,0 \%)$ & $137(17,5 \%)$ & $121(15,5 \%)$ & $783(100 \%)$ \\
\hline $20-25$ anos & $627(68,8 \%)$ & $91(10,0 \%)$ & $193(21,2 \%)$ & $911(100 \%)$ \\
\hline $26-40$ anos & $1.232(74,6 \%)$ & $180(10,9 \%)$ & $239(14,5 \%)$ & $1.651(100 \%)$ \\
\hline 41 a 65 anos & $1.990(82,1 \%)$ & $306(12,6 \%)$ & $128(5,3 \%)$ & $2.424(100 \%)$ \\
\hline + de 65 anos & $522(87,1 \%)$ & $56(9,4 \%)$ & $21(3,5 \%)$ & $599(100 \%)$ \\
\hline Total & $5.330(73,4 \%)$ & $1.146(15,8 \%)$ & $784(10,8 \%)$ & $7.260(100 \%)$ \\
\hline
\end{tabular}

FONTE: PESQUISA RURAL - EMATER, 1992 
QUADRO 6 - DISTRIBUIÇÃO DA POPULAÇÃO RURAL FEMININA DO RIO GRANDE

DO SUL, PELO TIPO DE TRABALHO (EM TEMPO INTEGRAL OU PARCIAL NO

ESTABELECIMENTO AGROPECUÁRIO OU FORA DO ESTABELECIMENTO), DE ACORDO A IDADE

\begin{tabular}{|l|l|l|l|l|}
\hline $\begin{array}{l}\text { Grupos de } \\
\text { idade }\end{array}$ & $\begin{array}{l}\text { Tempo integral no } \\
\text { estabelecimento }\end{array}$ & $\begin{array}{l}\text { Tempo parcial no } \\
\text { estabelecimento }\end{array}$ & $\begin{array}{l}\text { Fora do esta- } \\
\text { belecimento }\end{array}$ & Total \\
\hline $7-14$ anos & $437(51,0 \%)$ & $335(39,1 \%)$ & $85(9,9 \%)$ & $857(100 \%)$ \\
$15-19$ anos & $372(57,0 \%)$ & $134(20,5 \%)$ & $147(22,5 \%)$ & $653(100 \%)$ \\
$20-25$ anos & $398(61,7 \%)$ & $65(10,1 \%)$ & $182(28,2 \%)$ & $645(100 \%)$ \\
$26-40$ anos & $1.039(69,7 \%)$ & $164(11,0 \%)$ & $288(19,3 \%)$ & $1.491(100 \%)$ \\
41 a 65 anos & $1.863(82,6 \%)$ & $216(9,6 \%)$ & $175(7,8 \%)$ & $2.254(100 \%)$ \\
+ de 65 anos & $431(80,8 \%)$ & $67(12,6 \%)$ & $35(6,6 \%)$ & $533(100 \%)$ \\
Total & $4.540(70,6 \%)$ & $981(15,2 \%)$ & $912(14,2 \%)$ & $6.433(100 \%)$ \\
\hline
\end{tabular}

FONTE: PESQUISA RURAL - EMATER, 1992

e em empregos fora da agricultura apresenta-se de maneira diversa em diferentes regióes do Estado. Como é possível verificar no quadro 7, as regiões onde uma maior proporção de homens e de mulheres trabalha em tempo integral são Planalto e Alto Uruguai, seguidas pelas regiões Noroeste e Vale do Taquari, todas situadas na antiga zona florestal do Estado, caracterizada principalmente pela incidência da agricultura familiar fundamentada em pequenos e médios estabelecimentos. Quando se considera o trabalho fora da agricultura, tanto para os homens como para as mulheres, destaca-se a Depressão Central.

São poucos os dados existentes sobre as principais atividades da população que sai do meio rural ou que tem atividades em tempo parcial na agricultura. De acordo com Sergio Schneider, ${ }^{20}$ nas regiões do Vale do Caí, Vale do Taquari, Encosta da Serra e Vale dos Sinos, muitos filhos de agricultores tornaram-se operários das indústrias de calçados da região ${ }^{21}$ De fato, o desenvolvimento desse setor industrial atraiu migrantes rurais de praticamente todas as regióes do Estado, mas também viabilizou, para os agricultores das regiões onde se localizam as indústrias, o emprego industrial combinado com a utilização do estabelecimento agropecuário como domicílio. Deve-se considerar, ainda, a construção civil, como um setor que, por demandar uma mão-de-obra pouco especializada, absorve parte considerável dos emigrantes rurais do sexo masculino. Em algumas regiões do Estado, por outro lado, como no Litoral Norte, muitos jovens oriundos do meio rural tornaram-se caminhoneiros. Para as mulheres jovens, o setor de serviços (principalmente o doméstico) é um dos principais absorvedores de sua mão-de-obra.

\footnotetext{
${ }^{20}$ SCHNEIDER, 1995 e 1996.

${ }^{21}$ Em 1989, a indústria de calçados era o principal gênero industrial em número de empregos no Estado, seguida pela indústria de produtos alimentares, com respectivamente $27 \%$ e 14,6\% da mão-de-obra empregada na indústria do Rio Grande do Sul (BANDEIRA, 1994, p. 41, tab. 18). O emprego nessas indústrias apresentava peso diferenciado nas três regiões em que foi dividido o Estado: na região Nordeste, a indústria de calçados respondia por $32,4 \%$ dos empregos industriais da região, enquanto que a indústria de produtos alimentícios ocupava 6,6\% dos operários; na região Norte, as indústrias de calçados e de produtos alimentícios ocupavam respectivamente $20,3 \%$ e $20,2 \%$ dos operários; na região Sul, esses dois gêneros industriais ocupavam respectivamente $2,3 \%$ e $59,0 \%$ dos operários (BANDEIRA, 1994, , p. 41, Tab. 18).
} 
QUADRO 7 - DISTRIBUIÇÃO DA POPULAÇÃO RESIDENTE NOS ESTABELECIMENTOS AGROPECUÁRIOS, PELO TIPO DE TRABALHO, ENTRE HOMENS E MULHERES, POR REGIÃO - RIO GRANDE DO SUL, 199

\begin{tabular}{|c|c|c|c|c|c|c|}
\hline & \multicolumn{3}{|c|}{ Homens que trabalham } & \multicolumn{3}{|c|}{ Mulheres que trabalham } \\
\hline Regiões & $\begin{array}{l}\text { Tempo } \\
\text { integral }\end{array}$ & $\begin{array}{l}\text { Tempo } \\
\text { parcial }\end{array}$ & $\begin{array}{l}\text { Fora do } \\
\text { estabel. }\end{array}$ & $\begin{array}{l}\text { Tempo } \\
\text { integral }\end{array}$ & $\begin{array}{l}\text { Tempo } \\
\text { parcial }\end{array}$ & $\begin{array}{l}\text { Fora do } \\
\text { estabelecim. }\end{array}$ \\
\hline $\begin{array}{l}\text { Campa- } \\
\text { nha }\end{array}$ & $\begin{array}{l}323 \\
(68.3 \%)\end{array}$ & $\begin{array}{l}93 \\
(19.7 \%)\end{array}$ & $\begin{array}{l}57 \\
(12.0 \%)\end{array}$ & $\begin{array}{c}264 \\
(70.2 \%)\end{array}$ & $\begin{array}{l}57 \\
(15.2 \%)\end{array}$ & $\begin{array}{l}55 \\
(14.6 \%)\end{array}$ \\
\hline Serra & $\begin{array}{l}427 \\
(66,1 \%)\end{array}$ & $\begin{array}{l}132 \\
(20,4 \%)\end{array}$ & $\begin{array}{l}87 \\
(13,5 \%)\end{array}$ & $\begin{array}{c}381 \\
(68,8 \%)\end{array}$ & $\begin{array}{l}74 \\
(13,3 \%)\end{array}$ & $\begin{array}{l}99 \\
(17,9 \%)\end{array}$ \\
\hline $\begin{array}{l}\text { Vale } \\
\text { Taquari }\end{array}$ & $\begin{array}{l}944 \\
(74,1 \%)\end{array}$ & $\begin{array}{l}169 \\
(13,3 \%)\end{array}$ & $\begin{array}{l}160 \\
(12,6 \%)\end{array}$ & $\begin{array}{l}863 \\
(76,0 \%)\end{array}$ & $\begin{array}{l}154 \\
(13,6 \%)\end{array}$ & $\begin{array}{l}118 \\
(10,4 \%)\end{array}$ \\
\hline Planalto & $\begin{array}{l}492 \\
(85,0 \%)\end{array}$ & $\begin{array}{l}60 \\
(10,3 \%)\end{array}$ & $\begin{array}{l}27 \\
(4,7 \%) \\
\end{array}$ & $\begin{array}{l}399 \\
(77,3 \%)\end{array}$ & $\begin{array}{l}72 \\
(14,0 \%)\end{array}$ & $\begin{array}{l}45 \\
(8,7 \%)\end{array}$ \\
\hline Zona Sul & $\begin{array}{l}566 \\
(70,9 \%)\end{array}$ & $\begin{array}{l}152 \\
(19,0 \%)\end{array}$ & $\begin{array}{l}81 \\
(10,1 \%)\end{array}$ & $\begin{array}{l}471 \\
(64,5 \%)\end{array}$ & $\begin{array}{l}123 \\
(16,9 \%)\end{array}$ & $\begin{array}{l}136 \\
(18,6 \%)\end{array}$ \\
\hline $\begin{array}{l}\text { Metropo- } \\
\text { litana }\end{array}$ & $\begin{array}{l}674 \\
(69,0 \%)\end{array}$ & $\begin{array}{l}194 \\
(19,8 \%)\end{array}$ & $\begin{array}{l}109 \\
(11,2 \%)\end{array}$ & $\begin{array}{l}576 \\
(67,3 \%)\end{array}$ & $\begin{array}{l}150 \\
(17,5 \%)\end{array}$ & $\begin{array}{l}130 \\
(15,2 \%)\end{array}$ \\
\hline $\begin{array}{l}\text { Depres- } \\
\text { são C. }\end{array}$ & $\begin{array}{l}689 \\
(67,4 \%)\end{array}$ & $\begin{array}{l}124 \\
(12,1 \%)\end{array}$ & $\begin{array}{l}209 \\
(20,5 \%)\end{array}$ & $\begin{array}{l}558 \\
(58,9 \%)\end{array}$ & $\begin{array}{l}115 \\
(12,2 \%)\end{array}$ & $\begin{array}{l}274 \\
(28,9 \%)\end{array}$ \\
\hline Noroeste & $\begin{array}{l}767 \\
(76,8 \%)\end{array}$ & $\begin{array}{l}169 \\
(16,9 \%)\end{array}$ & \begin{tabular}{|l}
63 \\
$(6,3 \%)$
\end{tabular} & $\begin{array}{l}643 \\
(74,2 \%)\end{array}$ & $\begin{array}{l}168 \\
(19,4 \%)\end{array}$ & $\begin{array}{l}55 \\
(6,4 \%)\end{array}$ \\
\hline $\begin{array}{l}\text { Alto } \\
\text { Uruguai }\end{array}$ & $\begin{array}{l}553 \\
(84,0 \%)\end{array}$ & $\begin{array}{l}76 \\
(11,6 \%)\end{array}$ & $\begin{array}{l}29 \\
(4,4 \%) \\
\end{array}$ & $\begin{array}{l}487 \\
(79,7 \%)\end{array}$ & $\begin{array}{l}80 \\
(13,1 \%)\end{array}$ & $\begin{array}{l}44 \\
(7,2 \%)\end{array}$ \\
\hline Total RS & $\begin{array}{l}5436 \\
(73,2 \%)\end{array}$ & $\begin{array}{l}1169 \\
(15,7 \%)\end{array}$ & $\begin{array}{l}822 \\
(11,1 \%)\end{array}$ & $\begin{array}{l}4643 \\
(70,4 \%)\end{array}$ & $\begin{array}{l}993 \\
(15,1 \%)\end{array}$ & $\begin{array}{l}956 \\
(14,5 \%)\end{array}$ \\
\hline
\end{tabular}

FONTE: PESQUISA RURAL - EMATER, 1992 
Na pesquisa realizada em ljuí, foi possível verificar algumas especificidades sobre o destino profissional dos filhos dos agricultores. Em primeiro lugar, mais da metade dos filhos e das filhas dos agricultores (embora os homens em proporção superior às mulheres) tornaram-se agricultores, os homens porque herdaram (diretamente ou por meio da esposa) ou compraram terra e as mulheres porque casaram com um agricultor (viabilizando, assim, em alguns casos, sua participação na herança da terra familiar). Em segundo lugar, a segunda ocupação preferencial para as mulheres foi a de professora, seguida da de funcionária (civil ou pública), enquanto que para os homens a segunda ocupação preferencial foi a de empregado no setor de serviços ou operário, seguida de ocupações que representam ascensão social, como comerciante ou autônomo, engenheiro ou técnico e profissionais liberais. ${ }^{22}$

\subsection{Herança da terra}

De um modo geral, as filhas mulheres não herdam a terra, a não ser que seu marido seja agricultor. Como indicam Zuleide Teixeira, Helena Carvalho e Mireya Suárez,

mesmo que em termos legais as mulheres tenham direito à titularidade da propriedade, este direito é impedido pelos valores e costumes das comunidades e pelo fato de o interlocutor privilegiado dos órgãos que executam as políticas do setor agrícola ser o homem/chefe de família, a quem atribuem a responsabilidade pela unidade produtiva. ${ }^{23}$

No passado, os agricultores tinham muitos filhos - como indicamos acima, a taxa de fecundidade rural, para o Rio Grande do Sul, era de 5,62 em 1970 - e, à medida que os filhos do sexo masculino ficavam adultos, os pais procuravam proporcionar terras para todos, resultando na divisão dos estabelecimentos agropecuários em tamanhos bastante reduzidos e na ida de membros da nova geração para regiões com terras mais baratas, isto é, para as novos espaços da fronteira agrícola (individualmente ou através de projetos de colonização ou de 'reforma agrária'). As filhas recebiam um dote, na maioria das vezes consistindo no enxoval, em alguns utensílios domésticos e em uma vaca. Um dos filhos geralmente o mais novo, pois os filhos mais velhos saíam da casa à medida que se tornavam adultos e constituíam um novo lar - permanecia com os pais e tornava-se o herdeiro da casa e do lote de terra familiar, comprometendo-se a cuidar dos pais em sua velhice. Mais recentemente, a maioria dos casais do meio rural tem em média apenas dois ou três filhos - como indicamos acima, a taxa de fecundidade rural, para o Rio Grande do Sul, era de 2,62 em 1995 -, mas os estabelecimentos já estão com um tamanho tão reduzido que a divisão entre os herdeiros tornou-se praticamente inviável (inclusive de forma legal, pois o Estatuto da Terra fixa limites à partilha dos estabelecimentos agropecuários em lotes de tamanho inferiores ao Módulo Rural - o qual estipula o mínimo necessário para garantir a sobrevivência de uma família, diferindo de acordo com as condições do solo e da produção regional) e o valor das terras está acima da capacidade de acumulação de recursos financeiros da maioria dos pequenos produtores familiares. O Código Civil prevê a igualdade entre todos os herdeiros, o que, na impossibilidade de divisão legal da terra, na prática só pode ocorrer se, após o falecimento de um ou de ambos os pais, a terra seja vendida e o dinheiro repartido entre os herdeiros. Verifica-se, no entanto, que alguns arranjos são feitos entre os herdeiros, quando um filho ou uma filha (caso seja casada com um agricultor) tenha demonstrado interesse em continuar produzindo no estabelecimento familiar. Verificase, também, com freqüência, no Rio Grande do Sul, a ocorrência de parcerias (ou

22 BRUMER E GIACOBBO, 1993.

${ }^{23}$ TEIXEIRA, CARVALHO E SUÁREZ, 1994, p. 71. 
associações) familiares, em que um ou dois filhos ou genros trabalham junto com o pai ou sogro no estabelecimento familiar, sem efetivar a partilha legal da terra.

Além dos aspectos examinados acima, tanto a migração dos jovens de ambos os sexos como a maior propensão de moças do que de rapazes do meio rural a migrar são também influenciadas pelas mudanças ocorridas nas aspirações dos jovens, proporcionadas pelo desenvolvimento dos meios de comunicação e de transporte, que aproximam o meio rural e o meio urbano, trazendo informações e viabilizando o maior contato dos jovens do meio rural com o meio urbano.

Essas mudanças parecem ter um efeito maior sobre as moças do que sobre os rapazes, em parte devido ao fato de que elas têm, em média, níveis de escolaridade mais elevados do que eles. Isso ocorre porque, de um modo geral, sabendo que serão preteridas na partilha da terra familiar ou na obtenção de um emprego estável no meio rural, ou rejeitando uma situação semelhante a de suas mães, as moças investem mais do que os rapazes em sua educação, com vistas a uma possível migração para a zona urbana. Os dados da Pesquisa Nacional por Amostra de Domicílios (PNAD), de 1995, por exemplo, permitem verificar que a maioria da população rural do Rio Grande do Sul tem quatro ou cinco anos de escolaridade $(47,0 \%$ da população masculina e $45,7 \%$ da população feminina de 10 anos ou mais de idade), enquanto que a população rural com mais de cinco anos de escolaridade é representada por $19,8 \%$ dos homens e $22,3 \%$ das mulheres rurais.

Em suas análises sobre o processo de reprodução social dos agricultores franceses, apesar da evidência empírica da existência de relação entre as condições econômicas e as perspectivas de reprodução social dos agricultores, Patrick Champagne ${ }^{24}$ considera que essa relação é apenas indireta, pois, no fundo, "a recusa dos filhos de suceder aos pais é, em primeiro lugar, recusa do modo de vida dos pais, a crise de reprodução sendo aqui uma crise de identidade social". ${ }^{25}$ Isso significa que, nas representações de muitos jovens do meio rural, há uma desvalorização da atividade agrícola tradicional. De modo particular, Patrick Champagne ${ }^{26}$ verificou que, quando comparada com outras atividades, a agricultura é vista pelos jovens, mas principalmente pelas moças, mais negativa do que positivamente. Entre os aspectos negativos são destacados, principalmente, a ausência de férias, de fins de semana livres e de horários de trabalho regulares; a atividade agrícola penosa, dura e difícil, submetendo os trabalhadores ao calor e ao frio e a posições de trabalho pouco confortáveis; e os rendimentos baixos, irregulares e aleatórios. Entre os aspectos positivos, destaca-se a visão de que o agricultor permanece sendo um trabalhador livre, que não depende de um patrão.

As representações dos jovens, por outro lado, como indica o autor, como resultado da socialização, refletem a visão de mundo e a concepção da profissão dos pais, bem como sua percepção mais ou menos pessimista das perspectivas futuras. ${ }^{27}$ Nesse sentido, é surpreendente a visão predominantemente negativa da atividade agrícola, tendo em vista o reconhecimento, pelos adultos entrevistados, da melhoria tanto das condições de vida (conforto doméstico, alimentação) como das condições de trabalho (mecanização, que torna o trabalho menos penoso). Como indica o autor, provavelmente o importante, nessas considerações, é a perspectiva comparativa entre a percepção de suas condições

\footnotetext{
${ }^{24}$ CHAMPAGNE, 1986a e 1986b.

${ }^{25}$ CHAMPAGNE, 1986a, p. 77.

${ }^{26}$ CHAMPAGNE, 1986a.

${ }^{27}$ CHAMPAGNE, 1986a, p. 84.
} 
de vida e as condições de vida dos trabalhadores urbanos, levando-se em conta principalmente o lazer, o tempo livre e a natureza e o volume das preocupações. ${ }^{28}$

Como indicamos anteriormente, existem diferenças regionais no que diz respeito à absorção da população em atividades agropecuárias, havendo uma estreita relação entre as condições de trabalho e obtenção de renda no meio rural e os índices migratórios (com o resultante do maior ou menor 'envelhecimento' da população). Assim, com base nos dados apresentados acima, podem-se estabelecer relações entre as regiões com população mais idosa (provavelmente devido à emigração proporcionalmente maior da população jovem) e a utilização da terra para criação de gado, enquanto que as regiões que contam com uma população rural relativamente mais jovem apresentam uma agricultura mais dinâmica e mais diversificada, com um uso mais intensivo das terras e, por conseqüência, com uma maior utilização de mão-de-obra.

Nos quadros 5 e 6, examina-se a relação entre idade e grau de emprego no estabelecimento familiar da população ativa. A análise dos dados permite evidenciar, entre outros aspectos: a) a utilização do trabalho infantil (crianças com 14 anos ou menos), tanto em tempo integral como em tempo parcial no estabelecimento, e também, em menor proporção, fora do estabelecimento; b) a participação mais marcante de jovens e adultos entre 15 e 40 anos em trabalhos fora do estabelecimento familiar, quando comparados com os adultos com mais de 40 anos; c) a participação relativamente maior de mulheres do que de homens em trabalhos fora do estabelecimento familiar e, inversamente, a participação mais acentuada de homens do que de mulheres em trabalho em tempo integral no estabelecimento familiar.

No quadro 7, são mostradas as diferenças existentes entre as regiões em que foi dividido o Estado do Rio Grande do Sul na pesquisa da Emater, em termos da ocupação da mão-de-obra residente nos estabelecimentos rurais, em tempo integral ou parcial no próprio estabelecimento ou fora do mesmo. As regiões Planalto e Alto Uruguai, seguidas das regiões Noroeste e Vale do Taquari, são as que apresentam as maiores proporções da população ativa com trabalho em tempo integral no próprio estabelecimento. Por outro lado, as regiões Campanha, Serra, Depressão Central e Metropolitana são as que apresentam as menores proporções de residentes nos estabelecimentos com trabalho em tempo integral no próprio estabelecimento.

Na comparação entre os dados do quadro 7 e os do quadro 2, é possível constatar a associação entre a distribuição por idade e a ocupação da mão-de-obra, havendo coincidência entre as regiões com maior proporção da população com mais de 64 anos e menor grau de ocupação em tempo integral, e ocorre o inverso nas regiões com menor proporção da população com mais de 64 anos e maior grau de ocupação em tempo integral no estabelecimento familiar, com exceção da região Depressão Central, que registra uma relativamente baixa proporção de idosos e uma das proporções mais reduzidas de trabalhadores em tempo integral no estabelecimento familiar.

Schneider ${ }^{29}$ mostra que, enquanto a agricultura da região noroeste do Estado se modernizou, estimulada pelo desenvolvimento da cultura da soja a partir dos anos 1960, nas regiões das Colônias Velhas (particularmente nas regiões do Vale dos Sinos, Encosta da Serra, Vale do Caí e Vale do Taquari) a agricultura manteve seu caráter colonial tradicional, até sofrer mudanças radicais a partir dos anos 1980, por dois processos concomitantes: o abandono de grande parte da agricultura comercial e uso das terras

${ }^{28}$ CHAMPAGNE, 1986a, p. 85.

${ }^{29}$ SCHNEIDER, 1995 e 1996. 
para a plantação de acácias destinadas a alimentar a indústria moveleira e o emprego de grande parte dos agricultores nas indústrias coureiro-calçadistas que se instalaram nessas regiões, muitos dos quais mantendo uma atividade agrícola em tempo parcial em seus estabelecimentos rurais.

\section{Benefícios sociais}

O Rio Grande do Sul sediou, desde o final dos anos 1970, uma das mobilizações de mulheres rurais mais importantes do Brasil. ${ }^{30} \mathrm{~A}$ emergência dessa mobilização inseriu-se em um contexto de lutas que incluíram a luta pela terra (cuja primeira manifestação após o golpe militar de 1964 foi a invasão da Fazenda Anoni, em 1978, evoluindo para a formação de um movimento organizado, o Movimento dos Trabalhadores Sem Terra - MST, durante a década de 80 ) e a luta contra a construção de barragens (que eclodiu no Paraná no final da década de 70 e logo depois se manifestou no Rio Grande do Sul).

Tendo inicialmente como objetivos melhorias no atendimento médico e hospitalar aos pequenos produtores rurais, o movimento das mulheres logo em seguida passou a reivindicar o enquadramento das mulheres como beneficiárias diretas da Previdência Social. Durante a década de 80 , os objetivos do movimento tornaram-se mais complexos, pois, para terem acesso aos benefícios solicitados, as mulheres deveriam ser reconhecidas como trabalhadoras rurais, tanto pelos órgãos governamentais responsáveis pela atribuição dos benefícios, como pelos sindicatos de trabalhadores rurais.

A reivindicação de direitos sociais às mulheres trabalhadoras rurais parecia ser tão legítima que era apoiada por diferentes agentes externos. Na década de 80 , assim, era possível perceber a atuação de três grupos diferenciados, com base em apoios distintos: - movimento das "Margaridas", apoiado pela Central Única dos Trabalhadores (CUT) e pelo Partido dos Trabalhadores (PT), que defendiam a integração das lutas das trabalhadoras rurais com as das trabalhadoras urbanas; o movimento das "trabalhadoras rurais", apoiado pela Federação dos Trabalhadores na Agricultura (FETAG), Comissão Pastoral da Terra (CPT), Emater/RS e Legião Brasileira de Assistência (LBA), criticado pelo movimento das "Margaridas" por evitar a discussão de classe e procurar incorporar tanto trabalhadoras como empregadoras rurais; e o movimento das "mulheres da roça", apoiado por sindicatos rurais de oposição à FETAG e pela ala progressista da lgreja, ${ }^{31}$ e que defendia "a participação efetiva, e não apenas simbólica, das trabalhadoras rurais nos movimentos de massa, tais como sindicato e central de trabalhadores", ${ }^{32}$ sustentando, ainda, que "as trabalhadoras rurais devem desenvolver um espaço próprio de organização e mobilização como forma de poderem avançar na conquista de seus direitos". ${ }^{33}$ Após a promulgação da nova legislação, as mulheres rurais passaram a ser representadas por um 'movimento', o Movimento das Mulheres Trabalhadoras Rurais (MMTR), baseado em uma forte representação regional e que defende a autonomia do movimento diante de outros movimentos sociais e organizações.

O MMTR foi fundado em 1989, durante o Primeiro Encontro Estadual das Mulheres Trabalhadoras Rurais. Esse movimento foi criado com base em uma forte representação regional e em uma liderança de aproximadamente 500 mulheres, muitas delas com experiência anterior em atividades da Igreja, do MST e dos sindicatos de trabalhadores

\footnotetext{
30 Jussara PRÁ e Maria Noemi BRITO, 1988; BRUMER, 1993; Lynn STEPHEN, 1997.

${ }^{31}$ BRUMER, 1990.

32 BRUMER, 1990, p. 137.

${ }^{33}$ DOCUMENTO..., 1988, p. 7.
} 
rurais, caracterizando-se pela rejeição ao vínculo com a FETAG e pela insistência na autonomia do movimento diante de outros movimentos sociais e organizações, embora estreitasse os vínculos com a CPT, a CUT e o Movimento dos Trabalhadores Rurais Sem Terra (MST). ${ }^{34}$ Seus objetivos originais incluíam a saúde da mulher, a obtenção da licençamaternidade e a regularização dos direitos de aposentadoria atribuídos pela constituição de 1988. Além disso, o movimento defendia o reconhecimento do trabalho da mulher rural e sua integração individual nos sindicatos e cooperativas. ${ }^{35}$

A década de 80 registrou uma ampla mobilização das mulheres rurais, com a realização de diversos encontros locais e regionais. Desde 1981, a Federação dos Trabalhadores na Agricultura do Rio Grande do Sul passou a incluir a representação feminina em encontros de dirigentes sindicais. O primeiro encontro regional focalizando os problemas das mulheres trabalhadoras rurais do Rio Grande do Sul - o Primeiro Congresso da Mulher Agricultora-ocorreu em 1982, quando foi redigida a Cartilha da Mulher Trabalhadora, na qual se criticavam os conceitos de "unidade familiar" e de "chefe de família" contidos na legislação em vigor, considerados discriminatórios com relação às mulheres por negarIhes direitos sociais e o acesso à aposentadoria. ${ }^{36}$ Seguiram-se o Primeiro Encontro de Líderes Trabalhadoras, em 1983; e a celebração do 8 de março de 1984, em Erechim, que reuniu mais de mil mulheres trabalhadoras rurais. Em 1985, realizou-se outro encontro regional, organizado pela FETAG e pela Comissão Pastoral da Terra (CPT), que reuniu cerca de 10.000 mulheres rurais do Rio Grande do Sul, na capital do Estado, Porto Alegre. Vários encontros ocorreram em diferentes municípios do Estado, preparando a participação na caravana nacional que, em 1987, congregou 12.000 participantes em Brasília, com o objetivo de pressionar os parlamentares a incluir as demandas das mulheres trabalhadoras rurais na nova legislação que estava sendo preparada.

Graças a seu envolvimento massivo tanto nas lutas que precederam a aprovação da legislação referente à Previdência Social como nas que ocorreram posteriormente, no período em que essas leis estavam sendo regulamentadas por legislação específica, as mulheres que participaram das mobilizações têm a percepção de terem obtido uma conquista e uma vitória, contrariamente a benefícios concedidos aos trabalhadores brasileiros em algumas legislações trabalhistas anteriores (como o Estatuto da Terra e o Estatuto do Trabalhador Rural, por exemplo).

A Constituição de 1988 garantiu o acesso das mulheres rurais ao benefício da aposentadoria por idade, aos 55 anos, ${ }^{37}$ e a outros benefícios, tal como licençamaternidade remunerada. Uma das condições necessárias para o acesso aos benefícios da Previdência Social, principalmente no que diz respeito à aposentadoria, é a comprovação da condição de trabalhadoras rurais. ${ }^{38}$ Como a contribuição dos produtores rurais à Previdência Social - e ao mesmo tempo a comprovação da condição de

\footnotetext{
${ }^{34}$ Teixeira, CARVALHO e SUÁREZ, 1994.

35 STEPHEN, 1997.

${ }^{36}$ BRUMER, 1993.

${ }^{37}$ A nova legislação também beneficiou os homens rurais, que haviam tido acesso aos benefícios sociais com a criação do FUNRURAL em 1971, ao diminuir o limite de idade para aposentadoria de 65 para 60 anos e ao aumentar o valor mínimo da aposentadoria de meio para um salário mínimo.

${ }^{38}$ Por ocasião da promulgação da Constituição de 1988 e de sua regulamentação, pela Lei de Custeio da Previdência n 8.212, de 1991, e por outras leis que se seguiram até o final de 1992, a maioria das mulheres rurais nunca tinha contribuído diretamente para o sistema previdenciário nacional. Como indica Guilherme DELGADO, 1997, "o público beneficiário da previdência rural caracteriza-se majoritariamente como 'setor informal', ou seja, não contratado formalmente ou contribuinte regular do sistema". A legislação previu, então, a atribuição dos benefícios aos trabalhadores que em idade ativa trabalharam ou residiram no meio rural, independente de, ao receberem o benefício, terem domicílio rural ou urbano.
} 
trabalhador rural - é feita através de uma porcentagem da produção comercializada, para comprovar sua condição de trabalhadoras rurais, as mulheres precisaram ter seu nome incluído nas notas de venda dos produtos comercializados. Os homens não contestaram a inclusão do nome das mulheres nas notas de venda dos produtos do estabelecimento agropecuário ou no registro de notas diretamente em seu nome, em primeiro lugar, por não perderem nada com isso - a contribuição previdenciária global da unidade familiar de produção não aumentou, continuando a ser feita através de uma proporção da produção comercializada, ${ }^{39}$ e eles não tiveram seu poder, autonomia ou prestígio diminuídos; em segundo lugar, porque os benefícios atribuídos diretamente às mulheres representam uma quota de recursos adicionais que saem do 'bolso' do Estado e entram no 'bolso' dos membros da família (e por que não dizer, de uma certa maneira, no seu próprio bolso?). Ao mesmo tempo, a inclusão do nome das mulheres nos blocos de venda tem, para elas, um valor material e simbólico inquestionável. Valor material porque concretiza a comprovação de sua situação de trabalhadora rural, viabilizando assim seu acesso aos benefícios da Previdência Social. Valor simbólico porque torna visível e valoriza seu trabalho, representando, para elas, a conquista de uma dignidade que não tinham anteriormente.

Em uma avaliação sócio-econômica da Previdência Rural, Guilherme Delgado concluiu que "a previdência rural adquiriu importância quantitativamente expressiva no Brasil a ponto de se constituir no subsistema de seguro social de maior cobertura relativa, segundo o indicador de população assistida em relação a população potencialmente elegível". ${ }^{40} \mathrm{De}$ acordo com este pesquisador, a análise revelou "uma série de resultados sociais e econômicos de melhoria da eqüidade, decorrentes da aplicação dos dispositivos constitucionais universalizantes". Traduziu-se, também, "em discriminação positiva em termos de renda regional, proteção preferencial às mulheres e seguro de renda mínimo para idosos e inválidos". ${ }^{41}$

Como efeitos da nova legislação previdenciária, é possível observar, no Rio Grande do Sul, algumas mudanças. Comprova-se, por um lado, a observação de Delgado de que praticamente todos os homens e mulheres do meio rural que atingiram a idade mínima para a aposentadoria requereram e tiveram acesso ao benefício. ${ }^{42}$ Como os maridos em geral são mais idosos que as esposas, é muito comum encontrar casais de idosos beneficiando-se com um ingresso mensal de dois salários mínimos, ou, quando a mulher ou o homem são viúvos, recebendo cumulativamente sua aposentadoria e uma pensão relativa ao falecido cônjuge. O ingresso regular e mensal de recursos - de um modo geral inexistente quando se trata de produção agropecuária, cuja única exceção parece ser a produção de leite e de frangos -, por outro lado, tem efeitos sobre a gestão da unidade de produção, podendo ser percebidas as seguintes situações: quando existe sucessor (filho ou genro), os pais transferem a ele a administração do estabelecimento agropecuário, o que está favorecendo o ingresso dos filhos em idade mais jovem à chefia dos

\footnotetext{
39 Delgado informa que "a contribuição sobre a comercialização da produção agropecuária na forma em que passou a vigorar - a partir de dezembro de 1992 (Lei n 8.340, de 22/12/1992) para pessoa física, e de abril de 1994 (Lei n 8.870, de 15/04/1994) para pessoa jurídica - deveria gerar uma contribuição patronal para o INSS de no mínimo 2\% (pessoa física) e no máximo 2,5\% (pessoa jurídica)" (DELGADO, 1997, p. 39). A contribuição do 'segurado especial' (Lei n 8.861, de 01/07/1994) passou a ser de 2,2\% (DELGADO, 1997, p. 39), semelhante à de 'produtor rural pessoa física equiparado a autônomo' (Lei 8.540, de 01/04/1993, também calculada em 2,2\% da produção rural comercializada (DELGADO, 1997, p. 34).

40 DELGADO, 1997, p. 5.

${ }^{41}$ DELGADO, 1997, p. 6.

42 DELGADO, 1997.
} 
estabelecimentos agropecuários; quando não existe sucessor, o casal retrai consideravelmente as atividades produtivas destinadas à comercialização, mantendo apenas uma horta voltada a seu próprio consumo ou vende a propriedade e, com os recursos obtidos, compra uma casa e transfere-se para a cidade mais próxima, passando a viver dos benefícios das duas aposentadorias. ${ }^{43}$ Para o casal de idosos, a ida para a cidade representa principalmente o acesso mais facilitado - pela proximidade geográfica - a recursos médicos. Um outro efeito é o acesso das mulheres a uma renda própria, a ser por elas administrada, bastante diferente de sua situação anterior como 'membro não remunerado da família', em que os recursos disponíveis eram administrados pelos homens. Quando são viúvas e permanecem residindo com um dos filhos ou filhas, o fato de ter um dinheiro próprio significa que não estão vivendo 'de favor'. Ao contrário, passam a ser bem consideradas pelos demais membros da família, pois elas administram praticamente o único ingresso regular de recursos disponível.

É importante considerar que, graças aos efeitos do acesso das mulheres à aposentadoria rural, os dados apresentados no início do texto relativos à maior ou menor presença de idosos em algumas regiões do Rio Grande do Sul podem ter se modificado, tendo em vista que grande parte dos beneficiários de aposentadoria teve acesso a ela após a realização da coleta de dados da Emater/RS em 1991/1992.44

Após a promulgação da Constituição de 1988, uma nova caravana nacional de trabalhadoras rurais, em 1991, levou a Brasília representantes de 16 estados, ${ }^{45} \mathrm{com}$ a finalidade de reivindicar a regulamentação dos direitos sociais conquistados. Atualmente, o movimento das mulheres rurais ocupa um menor espaço na mídia, embora um grupo de mulheres rurais do Rio Grande do Sul continue ativo em torno do Movimento das Mulheres Trabalhadoras Rurais, e encontros municipais reunindo um grande número de mulheres ocorram anualmente, no dia 8 de Março, por ocasião da comemoração do Dia Internacional da Mulher.

Entre as questões atualmente levantadas pela liderança desse movimento estão, por um lado, a efetiva inclusão do nome das mulheres trabalhadoras rurais nos blocos de venda dos produtos dos estabelecimentos agropecuários e, por outro, a saúde da mulher trabalhadora rural. No que se refere à saúde, elas chamam a atenção para as conseqüências da dupla atividade das mulheres e das tarefas por elas executadas tanto na esfera produtiva como no âmbito doméstico, resultando em 'doenças dos nervos', problemas da coluna vertebral e outros males causados pela excessiva exposição ao sol e à umidade, esperando um atendimento especial por parte do Estado. Nesse sentido, é interessante verificar que, embora os problemas que enfrentam sejam uma decorrência de sua situação de trabalhadoras rurais e de sua condição feminina, suas reivindicações não são feitas aos homens, mas sim ao Estado.

Apesar de reconhecer a existência de desigualdades de gênero, as mulheres envolvidas no MMTR não fazem reivindicações significativas no sentido de anulá-las ou diminuí-las. A ausência de reivindicações referentes a uma maior eqüidade nas responsabilidades pelo trabalho doméstico, acesso ao conhecimento tecnológico da

\footnotetext{
${ }^{43}$ Um agrônomo da Emater/RS atuando na região da Campanha relatou que, em uma pesquisa recente feita no município de Pinheiro Machado, de 56 estabelecimentos incluídos, sete agricultores relataram que só estavam esperando a obtenção da aposentadoria para vender a propriedade, comprar uma casa e transferir-se para a cidade.

${ }_{44}$ De acordo com o relatório de DELGADO, 1997, o número total de aposentadorias rurais, no Brasil, variou de 2.371,7 mil, em 1991; para 3.051 mil, em 1992; para 3.989,3 mil, em 1993; para 4.307,2 mil, em 1994; e para 4.263,9 mil, em 1995.

45 TEIXEIRA, CARVALHO e SUÁREZ, 1994.
} 
produção agropecuária moderna, igualdade na herança da terra e na distribuição das atividades e do poder, por exemplo, pode indicar que as mulheres desejam melhorar sua situação, principalmente se puderem obter maiores benefícios do Estado, mas evitam o confronto com seus parceiros homens.

Em parte, a ausência de confronto nas relações de gênero resulta das dificuldades a serem enfrentadas pelas mulheres no caso de separação ou divórcio, em primeiro lugar, porque, não tendo renda própria, sua liberdade é bastante limitada; em segundo lugar, porque envolveria a divisão de um patrimônio familiar que é, ao mesmo tempo, um meio de produção e de reprodução; em terceiro lugar, porque uma mulher separada ou divorciada, assim como uma mulher solteira, dificilmente teria condições (por razões materiais e culturais) de, sozinha, administrar um estabelecimento rural, a não ser que tivesse filhos jovens ou adultos residindo com ela.

\section{Conclusões}

Através de uma análise qualitativa de dados obtidos tanto através de coletas de dados com base em questionários padronizados como em entrevistas baseadas em roteiros não-padronizados, foi possível, primeiramente, mostrar a ocorrência de uma migração rural-urbana mais acentuada de mulheres do que de homens, para, em um segundo momento, examinar fatores explicativos desse processo.

Na explicação da seletividade do processo migratório, considerou-se a divisão do trabalho por sexo e geração, a modernização da agricultura, a forma de inserção dos jovens nos estabelecimentos familiares de produção agropecuária e em trabalhos fora do estabelecimento, os padrões existentes de transmissão do patrimônio (fundamentalmente a terra) e, por último, os benefícios sociais aos quais as mulheres do meio rural tiveram acesso apenas nesta última década.

A principal questão teórica que deu corpo ao conjunto de fatores explicativos utilizados foi a desigualdade - principalmente a desigualdade de gênero -, mas também esteve subjacente a questão das condições de reprodução dos estabelecimentos familiares de produção agropecuária.

Procurou-se mostrar que, devido às desigualdades de gênero, que atribuem às mulheres (principalmente às mulheres jovens) uma posição subordinada na estrutura familiar - evidenciada na distribuição das atividades nas esferas de produção e de reprodução, do poder e do acesso à propriedade da terra -, as mulheres têm menores perspectivas profissionais e motivação para permanecer no meio rural do que os homens. Ao mesmo tempo, fatores externos, tais como o tipo de produção agrícola desenvolvida, o caráter intensivo ou extensivo da produção, o tamanho do estabelecimento e as necessidades de mão-de-obra e o grau de desenvolvimento industrial nas proximidades dos estabelecimentos agropecuários, podem criar oportunidades de emprego parcial ou total fora da agricultura, com a manutenção da residência do trabalhador no meio rural. Como essas oportunidades são distintas conforme as regiões, ocorrem diferenças regionais no que diz respeito à distribuição da população por idade e sexo. Além disso, modificações na legislação como o acesso a benefícios da aposentadoria rural e salário-maternidade - podem criar novas condições para a permanência das mulheres no meio rural.

\section{Referências bibliográficas}

ALONSO, José Antonio Fialho; BENETTI, Maria Domingues; BANDEIRA, Pedro Silveira. Crescimento econômico da região Sul do Rio Grande do Sul: causas e perspectivas. Porto Alegre: Fundação de Economia e Estatística Siegfried Emanuel Heuser, 1994. 
ALONSO, José Antonio Fialho; BANDEIRA, Pedro Silveira. "Considerações metodológicas sobre a divisão regional". In: ALONSO, José Antonio Fialho; BENETTI, Maria Domingues; BANDEIRA, Pedro Silveira. Crescimento econômico da região Sul do Rio Grande do Sul: causas e perspectivas. Porto Alegre: Fundação de Economia e Estatística Siegfried Emanuel Heuser, 1994. p. 213-227.

BANDEIRA, Pedro Silveira. "As raízes históricas do declínio da Região Sul". In: ALONSO, José Antonio Fialho; BENETTI, Maria Domingues; BANDEIRA, Pedro Silveira. Crescimento econômico da região Sul do Rio Grande do Sul: causas e perspectivas. Porto Alegre: Fundação de Economia e Estatística Siegfried Emanuel Heuser, 1994. p. 7-48.

BRUMER, Anita. "O sexo da ocupação: considerações teóricas sobre a inserção da mãode-obra feminina na força de trabalho". Revista Brasileira de Ciências Sociais, n. 8, v. 3, p. 20-38, out. 1988.

- "Considerações sobre uma década de lutas sociais no campo no extremo sul do Brasil (1978-88)". Ensaios FEE, n. 11, v. 1, p. 124-142, 1990.

"Mobilization and the Quest for Recognition: The Struggle of Rural Women in Southern Brazil for Access to Welfare Benefits." In: ABEL, Christopher, and LEWIS, Colin M. Welfare. Poverty and Development in Latin America. London: MacMillan Press, 1993. p. 405-20. "Transformações e estratégias produtivas na produção familiar na agricultura gaúcha". Cadernos de Sociologia, Porto Alegre: PPGS/UFRGS, v. 6 (Volume especial sobre "Produção familiar, processos e conflitos agrários"), p. 89-111, 1994.

"Qual a 'vocação' produtiva da agricultura familiar?: globalização, produção familiar e trabalho na agricultura gaúcha". In: TEDESCO, João Carlos (Org.). Agricultura familiar: realidades e perspectivas. Passo Fundo: EDIUPF, 1999. p. 219-49.

BRUMER, Anita; FREIRE, Nádia Maria Schuch. "O trabalho da mulher na pequena produção agrícola". Revista do Instituto de Filosofia e Ciências Humanas da Universidade Federal do Rio Grande do Sul, ano XI/XI, p. 305-322, 1983/1984.

BRUMER, Anita; GIACOBBO, Elisa Olívia. "A mulher na pequena agricultura modernizada". Humanas, Revista do Instituto de Filosofia e Ciências Humanas da Universidade Federal do Rio Grande do Sul, v. 16, n. 1, p. 139-156, jan./jun. 1993.

CHAMPAGNE, Patrick. "Elargissement de l'espace social et crise de l'identité paysanne". Cahiers d'Economie et Sociologie Rurales, n. 3, p. 73-89 déc. 1986a.

."La reproduction de l'identité". Actes de la Recherche en Sciences Sociales, n. 65, p. 41-64, nov. 1986b.

DELGADO, Guilherme C. Previdência rural: relatório de avaliação sócio-econômica. Projeto IPEA/MPAS - Avaliação Sócio-Econômica da Previdência Rural - 1991/1995. Brasília, janeiro de 1997.

DOCUMENTO da Organização das Mulheres Trabalhadoras Rurais do Rio Grande do Sul. Passo Fundo, maio/jun. 1988.

DURSTON, John. "Juventud rural en Brasil y Mexico: reduciendo la invisibilidad". Disponível em: http://www.ilo.org/public/spanish/region/ampro/cinterfor/temas/youth/doc/not/libro22/ index.htm. s/d.

FLORA, Cornelia Butler, and SANTOS, Blas. "Women in Farming Systems in Latin America." In: NASH, Helen (ed.). Women and Change in Latin America. Massachusetts: Bergin \& Garvey, 1986, p. 208-228.

FREIRE, Nadia Maria Schuch. Mulher, trabalho e capital no campo: um estudo da pequena produção em Cruzeiro do Sul - RS. 1983. Dissertação (Mestrado em Sociologia Rural) Universidade Federal do Rio Grande do Sul, Porto alegre.

IBGE. Censo Demográfico de 1991: situação demográfica, social e econômica: primeiras 
considerações - estado do Rio Grande do Sul. Rio de Janeiro: Fundação Instituto Brasileiro de Geografia e Estatística, 1995a.

. Pesquisa Nacional por Amostra de Domicílios (PNAD) 1995 - Rio Grande do Sul. Rio

de Janeiro: Fundação Instituto Brasileiro de Geografia e Estatística, 1995b.

. Contagem da população. Rio de Janeiro: Fundação Instituto Brasileiro de Geografia e Estatística, 1996.

. Censo Agropecuário 1995/1996 - Rio Grande do Sul. Rio de Janeiro: Fundação Instituto Brasileiro de Geografia e Estatística, 1998.

LAMARCHE, Hughes (Coord.). A agricultura familiar: comparação internacional. Campinas: Ed. da UNICAMP, 1993. v. 1: Uma realidade multiforme.

NAVARRO, Zander; MORAES, Maria Stela.; MENEZES, Raul. "Pequena história dos assentamentos rurais no Rio Grande do Sul: formação e desenvolvimento". In: MEDEIROS, Leonilde Sérvolo; LEITE, Sérgio. (Orgs.). A formação dos assentamentos rurais no Brasil: processos sociais e políticas públicas. Porto Alegre: Ed. da UFRGS, 1999. p.19-59.

PAULILO, Maria Ignez Silveira. "O peso do trabalho leve". Ciência Hoje, Rio de Janeiro: SBPC, v. 5, n. 28, p. 64-70, jan./fev. 1987.

PRÁ, Jussara Reis; BRITO, Maria Noemi Castilhos. "Movimento de mulheres no Sul do Brasil: 1975 a 1987". Cadernos de Estudos do Programa de Pós-Graduação em Antropologia Social, Porto Alegre: UFRGS, n. 1, p. 28-41, dez. 1988.

SCHNEIDER, Sergio. "As transformações recentes da agricultura familiar no Rio Grande do Sul: o caso da agricultura em tempo parcial". Ensaios FEE, Porto Alegre, v. 16, n. 1, p.105-129, 1995.

- "Os colonos da indústria calçadista: a expansão industrial e as transformações da agricultura familiar no Rio Grande do Sul". Ensaios FEE, Porto Alegre, v. 17, n. 1, p. 298322, 1996.

STEPHEN, Lynn. "Relações de gênero: um estudo comparativo sobre organizações de mulheres rurais no México e no Brasil". In: NAVARRO, Zander (Org.). Política, protesto e cidadania no campo: as lutas sociais dos colonos e dos trabalhadores rurais no Rio Grande do Sul. Porto Alegre: Ed. da UFRGS, 1997. p. 29-61.

TEIXEIRA, Zuleide Araújo (Coord.); CARVALHO, Helena Mussi de; SUÁREZ, Mireya. Perspectiva de gênero na produção rural. Brasília: IPEA, jun. 1994.

\section{Gender and Agriculture: the Situation of Women in Agriculture in the State of Rio Grande do Sul}

Abstract: The paper examines the forms of insertion of women in the agricultural farm, with the purpose of explaining the gender selectivity of migration. Firstly, it deals with the population distribution, by sex and age groups, in different regions of the state of Rio Grande do Sul, in order to characterize the higher emigration of young women in comparison with other groups. Afterwards, it deals with the division of work by sex and age, the effects of modernization upon the agricultural work and the ways in which the farmers transfer their property to the children. Finally it discusses the possible effects of the access of rural women to the Social Security on their perspectives of remaining or not in the agricultural activity.

Key words: gender and agriculture, rural women, rural migration. 